\title{
A critical review of recent clinical practice guidelines on the diagnosis and treatment of non-neurogenic male lower urinary tract symptoms
}

\author{
Michael Erlano Chua, MD; ${ }^{*}$ Jonathan Mendoza, MD; ${ }^{+}$Manuel See IV, MD,* Ednalyn Esmena, MD,s \\ Dean Aguila, MD; Jan Michael Silangcruz, MD; ${ }^{*}$ Buenaventura Jose Reyes, MD; Saturnino Luna Jr, MD; \\ Marcelino Morales $J r, M D^{f}$
}

\begin{abstract}
*Institute of Urology, St. Luke's Medical Center, Manila, Philippines; ${ }^{\dagger}$ Department of Preventive and Community Medicine, St. Luke's College of Medicine, Manila, Philippines; ${ }^{\S}$ Comprehensive Pelvic Floor Center, St. Luke's Medical Center, Manila, Philippines; ${ }^{*}$ Clinical Information Management Service, St. Luke's Medical Center, Manila, Philippines; ${ }^{E}$ Department of Urology, National Kidney and Transplant Institute, Manila, Philippines
\end{abstract}

Cite as: Can Urol Assoc J 2015;9(7-8):E463-70 http://dx.doi.org/10.5489/cuaj.2424 Published online July 17, 2015.

\section{Abstract}

Introduction: We provide an overview of the quality of recent clinical clinical practice guidelines (CPGs) for non-neurogenic male lower urinary tract symptoms (LUTS) and summarize the recommendations for their diagnosis, assessment, and treatment. Methods: We systematically searched recent (2008-2013) CPGs for non-neurogenic male LUTS. Eligible CPGs were assessed and appraised using Appraisal of Guidelines, Research and Evaluation II (AGREE II) tool by a CPG-appraisal group. The appraisal scores for each guideline were summarized according to each domain and in total. A recommendation summary was made across the guidelines for diagnostics, conservative management, medical, minimally invasive therapy, and surgical management.

Results: A total of 8 guidelines were considered. According to AGREE II appraisal of guidelines, the National Institute for Health and Clinical Excellence (NICE), American Urological Association (AUA) and European Association of Urology (EAU) consistently scored high on the guideline domains assessed. Recommendations on diagnostics, conservative management, medical, and surgical management were consistent among the top 3 guidelines. However, we noted a discrepancy in recommending minimally invasive therapy as an alternative management of moderate to severe or bothersome non-neurogenic male LUTS secondary to benign prostatic enlargement (BPE); the NICE guideline, in particular, does not recommend using minimally invasive therapy.

Conclusion: The quality of recent CPGs on non-neurogenic male LUTS was appraised and summarized. The guidelines from NICE, AUA and EAU were considered highly compliant to the AGREE II proposition for guideline formation and development.

\section{Introduction}

Lower urinary tract symptoms (LUTS) are associated with a decline in overall quality of life and has a high propensity to progress with age. ${ }^{1,2}$ With the advent of evidence-based medicine, several clinical practice guidelines (CPGs) have been developed to help manage LUTS. However, quality and credibility concerns of these existing guidelines have risen., With such concerns, the AGREE Collaboration (Appraisal of Guidelines, Research and Evaluation) created a 23-item tool (AGREE II tool) targeting 6 quality-related domains to assess the quality of CPGs; this AGREE II tool has become an internationally well-accepted standard to evaluate guidelines., Faced with conflicting and inconsistent guidelines, urologists rightly maintain a healthy skepticism and are able to identify reliable guidelines. To determine the qualities, similarities and differences in standards of care across the available guidelines, we critically reviewed all available recent CPGs using the AGREE II tool for the diagnosis, assessment and treatment of non-neurogenic male LUTS.

\section{Methods}

Before we started this review, we consulted with a methodologist and content experts and we adhered to the PRISMA statement. ${ }^{7}$ We included all documents identified as CPGs endorsed by any international society or government organization providing recommendations to guide clinical decision-making in diagnosing and treating LUTS. We excluded narrative reviews, primary research, clinical or critical pathways, training manuals, patient and allied health professional guidelines, and technical guides. Any CPGs released prior to 2008 and or searches before 2005 were also excluded. Language was not a barrier for inclusion. CPGs for which development methods could not be verified 
Chua et al.

due to the original documents being unavailable were also excluded. Only the latest version of the CPG were included. If CPGs was already endorsed by a major umbrella professional organization, then the CPGs cited by its subsection or sub-organization were not considered due to redundancy.

\section{Clinical practice guideline search process}

Two physician reviewers independently perform a systematic literature search on September 1, 2013 for electronic databases (Fig. 1). A complex search strategy included both "MeSH" (Medical Subject Heading) and "free text" protocols. Specifically, the MeSH terms were "Prostatic Hyperplasia," "Lower Urinary tract Symptoms," and "Practice guideline." Multiple "free text" searches were performed by applying the following terms through all fields: "benign prostatic hyperplasia," "benign prostatic enlargement," "lower urinary tract symptoms," and "LUTS." Local experts of the field and regional professional organizations were contacted for any unpublished or draft guidelines.

\section{Appraisal of guidelines}

To critically appraise CPGs effectively and to reinforce consistency during appraisal, our research team (urologist, general practitioner, urodynamic registered nurse and clinical research analyst) worked with a clinical and methodologist facilitator. CPGs were individually appraised by each member and were rated according to each domain according to the AGREE II tool.

Evaluation results from all appraisers were collected and tabulated by the facilitator using Microsoft Excel 2013 (Washington, DC). A modified Delphi process was used to reach consensus if a wide discrepancy was noted (discrepancy $>20 \%$ per domain score). Consensus development was done for a maximum of 3 rounds of the Delphi process or until $<20 \%$ discrepancy per domain score was met. The mean item scores and standardized domain scores for each CPG was calculated by averaging the scores across the 4 reviewers. Standardized domain scores were calculated according to AGREE II tool manual ${ }^{8}$ as follows:

\section{Recommendation summary}

Obtained score - minimum possible score

Maximum possible score - minimum possible score

Two physician reviewers independently extracted the recommendation items using a standardized data extraction form. The extracted data included CPG characteristics and recommendations in LUTS management. Specifically, the included CPGs were summarized descriptively according to the diagnosis, evaluation, medical treatment, minimally invasive approach, and surgical management recommendations.

\section{Results}

\section{Guidelines acquisition and quality of guidelines}

Our guideline acquisition process revealed 10 eligible clinical practice guidelines for appraisal and summary (Fig. 1). We included the following guidelines: National Institute for Health and Clinical Excellence (NICE), ${ }^{9}$ American Urological Association (AUA), ${ }^{10}$ European Association of Urology (EAU), ${ }^{11}$ Japanese Urological Association (JUA) 2009 and 2011,12,13 Urological Association of Asia (UAA), ${ }^{14}$ Canadian Urological Association (CUA) 2010 and 2012,15,16 International Consultation on Urological Diseases (ICUD6), ${ }^{17}$ and British Association of Urological Surgeons (BAUS). ${ }^{18}$

The NICE guideline ${ }^{9}$ and $A \cup A^{10}$ and $E A U^{11}$ guidelines have the most comprehensive discussion, evidence collation and analysis, which yielded the highest overall scores; the $\mathrm{CUA}^{15,16}$ and BAUS ${ }^{18}$ (GP) guidelines, due to their limited topic coverage and discussion, ranked in the bottom two in terms of the quality of the guidelines according to

Table 1. AGREE appraisal for clinical practice guidelines: Summary of 6 domain mean standardized scores and overall mean scores of eligible guidelines

\begin{tabular}{|c|c|c|c|c|c|c|c|c|c|c|}
\hline Domains & NICE & AUA & EAU & $\begin{array}{l}\text { JUA } \\
2009\end{array}$ & $\begin{array}{l}\text { JUA } \\
2011\end{array}$ & UAA & $\begin{array}{l}\text { CUA } \\
2010\end{array}$ & $\begin{array}{l}\text { CUA } \\
2012\end{array}$ & ICUD & $\begin{array}{l}\text { BAUS } \\
\text { (GP*) }\end{array}$ \\
\hline Scope and purpose & 0.96 & 0.97 & 0.83 & 0.79 & 0.70 & 0.91 & 0.90 & 0.43 & 0.76 & 0.60 \\
\hline Stakeholder involvement & 0.90 & 0.83 & 0.77 & 0.61 & 0.64 & 0.70 & 0.61 & 0.16 & 0.52 & 0.31 \\
\hline Rigour of development & 0.91 & 0.87 & 0.87 & 0.57 & 0.62 & 0.55 & 0.61 & 0.18 & 0.64 & 0.14 \\
\hline Clarity of presentation & 0.99 & 0.92 & 0.86 & 0.79 & 0.70 & 0.78 & 0.76 & 0.20 & 0.64 & 0.49 \\
\hline Applicability & 0.82 & 0.65 & 0.58 & 0.43 & 0.49 & 0.51 & 0.48 & 0.12 & 0.45 & 0.23 \\
\hline Editorial independence & 0.70 & 0.65 & 0.98 & 0.10 & 0.75 & 0.88 & 0.60 & 0.33 & 0.65 & 0.18 \\
\hline Overall score & 0.88 & 0.81 & 0.81 & 0.55 & 0.65 & 0.72 & 0.66 & 0.24 & 0.61 & 0.33 \\
\hline
\end{tabular}

AGREE: Appraisal of Guidelines, Research and Evaluation; NICE: National Institute for Health and Clinical Excellence; AUA: American Urological Association; EAU: European Association of Urology; JUA: Japanese Urological Association; UAA: Urological Association of Asia; CUA: Canadian Urological Association; ICUD: International Consultation on Urological Diseases; BAUS: British Association of Urological Surgeons; GP: general practitioner. 


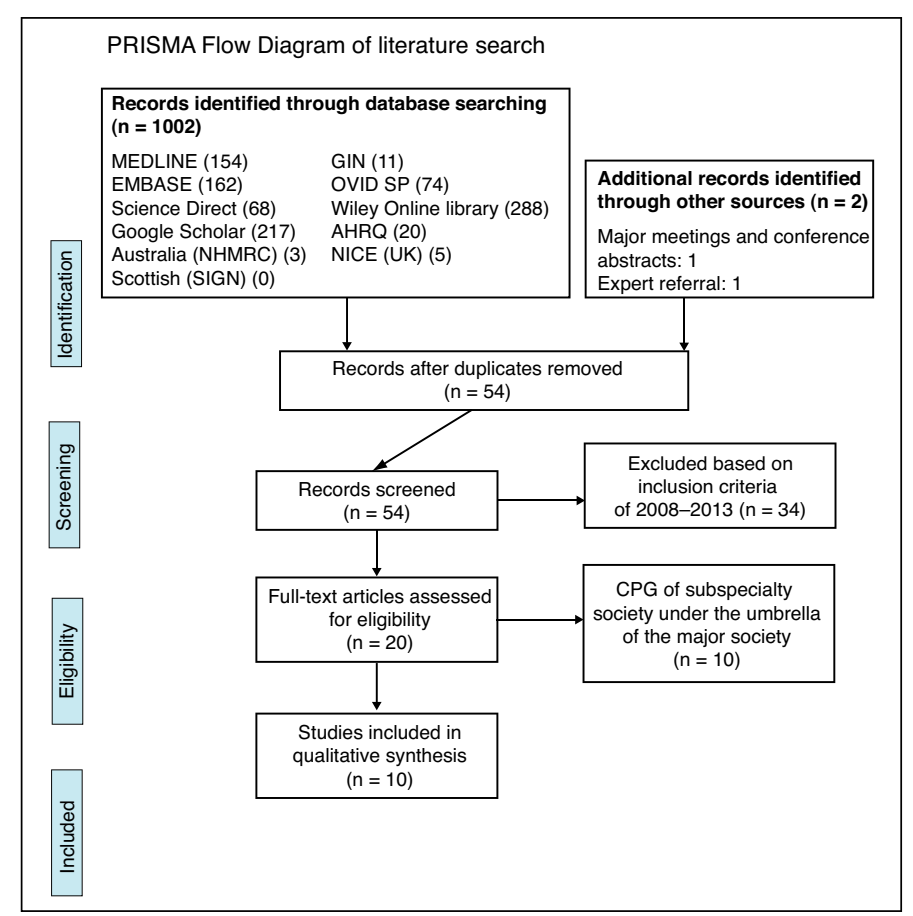

Fig. 1. PRISMA flow diagram of the literature search. Electronic Databases searched: Pubmed, EMBASE, OVID, Science Direct, Wiley Online library, Google scholar, Guideline International Network (GIN), Agency for Healthcare Research and Quality (AHRO), National Guidelines Clearinghouse (www.guideline.gov), Australia National Health and Medical Research Council, National Institute for Health and Clinical Excellence and Scottish Intercollegiate Guidelines Network (SIGN).

AGREE assessment (Table 1). In addition, the mean standardized scores of each domain per guideline showed that the among the 5 domains of AGREE appraisal, the highest mean standardized score per domain was consistent across the guidelines. Almost all of the guidelines had high scores in the domain on "scope and purpose" and "clarity of presentation." On the other hand, all the guidelines also had consistent low mean standardized scores in the domain of "applicability" and "editorial independence."

\section{Diagnostic recommendations}

All guidelines discussed the necessary basic diagnostic recommendations for LUTS, except the 2012 summary version of $\mathrm{CUA}^{16}$ guideline for the pharmacologic management of benign prostatic hyperplasia (BPH) and LUTS (Table 2).

All guidelines either recommended or mandated relevant medical history, focused physical examination, including a digital rectal examination (DRE), validated symptom assessment scoring tool, and urinalysis as the initial LUTS assessment. The International Prostate Symptom Score (IPSS) was the most commonly used validated scoring tool used to assess LUTS bother and severity.

Differences among the guidelines were in the use of serum creatinine as part of LUTS assessment. EAU, NICE,
JUA 2009, and UAA guidelines recommended its use as a screening tool for patients with suspected renal dysfunction. On the contrary, the EAU, JUA 2011, ${ }^{13}$ and CUA 2010 guidelines considered such a test an optional part of the initial blood analysis. The only guideline that did not consider its use in the initial evaluation of LUTS was the AUA guideline. This guideline considered the actuality that baseline renal insufficiency was not very common in men with $\mathrm{BPH}$ when compared to same age group in the general population.

As described in the NICE, JUA 2011 and UAA guidelines, ${ }^{14}$ uroflowmetry and measuring post-void residual (PVR) urine was generally an option for specialist assessment in selected patients, particularly where the facility was available. At least 2 flow rates must be obtained, with both voided urine volumes greater than $150 \mathrm{~mL}$, which helps identify patients who would benefit from surgery since the degree of obstruction can be determined by uroflowmetry. A maximum flow rate (Qmax) less than $10 \mathrm{~mL} / \mathrm{s}$ has a $90 \%$ correlation with pressure-flow study-proven obstruction, while most of men 60 years old and older with $>15 \mathrm{~mL} / \mathrm{s}$ will not experience obstruction.

Some diagnostic workups, including upper urinary tract imaging, pressure-flow study, and cystourethroscopy, were optional. Urine cytology was considered optional in the JUA 2009, ${ }^{12}$ CUA 2010 and UAA guidelines for patients with hematuria-suspected bladder cancer or in $\mathrm{BPH}$ patients not responding to medical treatment with predominant irritative LUTS. Pressure-flow studies were optional, particularly before surgery. According to the EAU guidelines, invasive urodynamic study was indicated only for patients who could not void $>150 \mathrm{~mL}$; have a Qmax $>15 \mathrm{~mL} / \mathrm{s}$; were $<50$ or $>80$ years of age; could void but have PVR $>300 \mathrm{~mL}$; were suspicious of having neurogenic bladder dysfunction; have bilateral hydronephrosis; had radical pelvic surgery or had previous unsuccessful (invasive) treatment. A prostatic ultrasound was specifically recommended in the EAU, JUA 2011 and UAA guidelines to accurately evaluate prostate volume, which was predictive of $\mathrm{BPH}$ progression.

All, but the NICE guideline, considered serum prostate-specific antigen (PSA) as an initial LUTS evaluation in patients with life expectancy of at least 10 years or in patients with DRE findings suggestive of prostate cancer. The NICE guideline considered this examination as optional for symptomatic BPH patients suggestive of bladder outlet obstruction (BOO), in patients with abnormal DRE findings, or in any patient who are concerned about prostate cancer.

Other elective examinations included cystourethrography in the UAA guideline for patients with history and uroflow assessment suggestive of urethral stricture. Pad testing was considered in the NICE guideline for select patients whose degree of urinary incontinence needs to be measured. Urine culture was mentioned in the JUA 2009 and the CUA 2010 guideline to confirm urinary tract infection (UTI). The sex- 
Chua et al.

ual function questionnaire was described in the CUA 2010 guideline as an optional assessment for males.

\section{Pharmacologic recommendations}

Generally, medical treatment was recommended across guidelines for patients with moderate to severe LUTS. It is strongly recommended that the benefits and risks of treatment be discussed with the patient (Table 3).

Currently, alpha-blockers are the mainstay for men with LUTS. Tamsulosin and terazosin were being recommended for LUTS treatment across all guidelines; while alfuzocin and doxazosin were recommended in most guidelines, except the JUA 2009 and 2011 guideline due to insufficient local data from Japan. Non-selective alpha-blockers, such as phenoxybenzamines and prazocin, were not recommended and excluded from analysis in the AUA guideline due to insufficient evidence. Newer alpha-blockers, such as urapidil, naftopidil and silodosin, were mentioned by the EAU and AUA guidelines as emerging alternatives; however, these drugs were already recommended in the JUA 2009 and 2011 guidelines.

As described in the AUA guideline, all 4 selective alpha adrenergic receptor blockers (doxazocin, terazocin, tamsulosin and alfuzosin) have comparable efficacy, with special dose titrations for doxazocin and terazocin to reduce the severity of orthostatic hypotension. All have similar adverse effects and must be avoided if taken with other anti-hypertensive medication. It was recommended to review LUTS symptoms in patients taking alpha blockers 4 to 6 weeks and then every 6 to 12 months.

Both finasteride and dutasteride decreased prostatic volume, increased peak urinary flow rate, and improved LUTS within 6 to 9 months. Finasteride was recommended in all guidelines, particularly for patients with an enlarged prostate gland (>30-40 g (ICUD6) and to prevent disease progression particularly cited by the EAU guideline for patients with $>40$ g or PSA concentration $>1.4-1.6 \mathrm{ng} / \mathrm{mL}$ (the only exceptions were the JUA 2009 and 2011 guidelines due to non-approval and lack of local evidence in Japan). The most common adverse effects associated with 5 - $\alpha$-reductase inhibitors (5-ARIs) were erectile dysfunction, decreased libido, or abnormal ejaculation. Physicians should review symptoms in patients taking 5 -ARIs at 3 to 6 months and then every 6 to 12 months. A combination of alpha-blockers and 5-ARIs was another option cited by most guidelines. The ICUD6 particularly described that the efficacy of the combined agent is higher than the single agent; this combination is basically offered as a long-term treatment for patients with bothersome or moderate-to-severe LUTS with an enlarged prostate.

Most of the guidelines, except the Japanese guidelines, have considered anticholinergic agents as an appropriate alternatives to manage LUTS secondary to $\mathrm{BPH}$ in men without an elevated PVR ( $>250-300 \mathrm{~mL}$ ) and when LUTS are predominantly storage symptoms. Its combination with an alpha-blocker is effective in improving irritative symptoms, and for select patients with $\mathrm{BOO}$ and concomitant detrusor

Table 2. Diagnostic recommendation across the guidelines

\begin{tabular}{|c|c|c|c|c|c|c|c|c|c|c|}
\hline Diagnostics & AUA & EAU & NICE & $\begin{array}{l}\text { JUA } \\
2009\end{array}$ & $\begin{array}{l}\text { JUA } \\
2011\end{array}$ & $\begin{array}{l}\text { CUA } \\
2010\end{array}$ & $\begin{array}{l}\text { CUA } \\
2012\end{array}$ & UAA & BAUS & ICUD6 \\
\hline History, physical exam, DRE & $\mathrm{R}$ & $\mathrm{R}$ & $\mathrm{R}$ & $M$ & $\mathrm{M}$ & $\mathrm{M}$ & ND & $\mathrm{M}$ & M & M \\
\hline Symptom score & $\mathrm{R}$ & $\mathrm{R}$ & $\mathrm{R}$ & $\mathrm{R}$ & M & $\mathrm{R}$ & ND & $\mathrm{R}$ & $\mathrm{R}$ & $\mathrm{R}$ \\
\hline Voiding diary & $\mathrm{R}$ & $\mathrm{R}$ & $\mathrm{R}$ & $\mathrm{R}$ & $\mathrm{O}$ & $\mathrm{O}$ & ND & $\mathrm{R}$ & $\mathrm{R}$ & $\mathrm{R}$ \\
\hline Urine analysis & $\mathrm{R}$ & $\mathrm{R}$ & $\mathrm{R}$ & M & M & M & ND & $\mathrm{R}$ & M & $\mathrm{R}$ \\
\hline Uroflowmetry & $\mathrm{O}$ & $\mathrm{O}$ & $\mathrm{O}$ & $\mathrm{O}$ & M & $\mathrm{O}$ & ND & $\mathrm{R}$ & $\mathrm{O}$ & $\mathrm{R}$ \\
\hline PVR measurement & $\mathrm{O}$ & $\mathrm{R}$ & $\mathrm{O}$ & $\mathrm{R}$ & M & $\mathrm{O}$ & ND & $\mathrm{R}$ & $\mathrm{O}$ & $\mathrm{R}$ \\
\hline Serum creatinine & NR & $\mathrm{R}$ & $\mathrm{R}$ & $\mathrm{R}$ & $\mathrm{O}$ & $\mathrm{O}$ & ND & $\mathrm{R}$ & ND & ND \\
\hline Serum PSA & $\mathrm{O}$ & $\mathrm{R}$ & $\mathrm{O}$ & M & M & $\mathrm{R}$ & ND & $\mathrm{R}$ & $\mathrm{R}$ & $\mathrm{R}$ \\
\hline Upper urinary tract imaging & $\mathrm{O}$ & $\mathrm{R}$ & $\mathrm{O}$ & $\mathrm{O}$ & $\mathrm{O}$ & $\mathrm{O}$ & ND & $\mathrm{O}$ & ND & $\mathrm{O}$ \\
\hline Prostate UTZ scan & $\mathrm{O}$ & $\mathrm{R}$ & $\mathrm{O}$ & ND & $\mathrm{R}$ & $\mathrm{O}$ & ND & $\mathrm{R}$ & $\mathrm{O}$ & $\mathrm{O}$ \\
\hline Pressure-flow study & $\mathrm{O}$ & $\mathrm{O}$ & $\mathrm{O}$ & ND & $\mathrm{O}$ & $\mathrm{O}$ & ND & $\mathrm{O}$ & $\mathrm{O}$ & $\mathrm{O}$ \\
\hline Cystourethroscopy & $\mathrm{O}$ & ND & $\mathrm{O}$ & ND & $\mathrm{O}$ & $\mathrm{O}$ & ND & $\mathrm{O}$ & ND & $\mathrm{O}$ \\
\hline Cysto-urethrography & ND & ND & ND & ND & ND & ND & ND & $\mathrm{O}$ & ND & ND \\
\hline Urine cytology & ND & ND & ND & $\mathrm{O}$ & ND & $\mathrm{O}$ & ND & $\mathrm{O}$ & ND & ND \\
\hline Sexual function questionnaire & ND & ND & ND & ND & ND & $\mathrm{O}$ & ND & ND & ND & ND \\
\hline Pad testing & ND & ND & $\mathrm{O}$ & ND & ND & ND & ND & ND & ND & ND \\
\hline Urine culture & ND & ND & ND & $\mathrm{R}$ & ND & ND & ND & ND & ND & ND \\
\hline
\end{tabular}

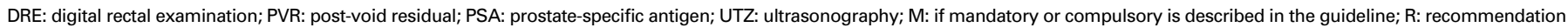

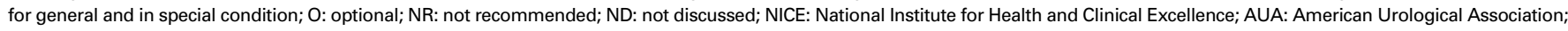

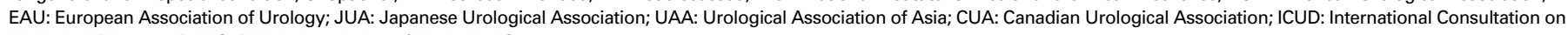
Urological Diseases; BAUS: British Association of Urological Surgeons. 
overactivity. Although the predominant adverse effect were dry mouth and flushes, patients on anticholinergics should be evaluated every 4 to 6 weeks until symptoms become stable, and every 6 to 12 months thereafter.

As cited by the NICE guideline, there was no increase in Qmax with PDE5 inhibitors. Only the EAU and UAA guidelines considered PDE5 inhibitors for LUTS patients with concomitant erectile dysfunction. The UAA guideline emphasized its use in combination with an alpha-blocker; this was well-tolerated and effective, yet there is a danger of hypotension. ${ }^{14}$

The EAU, NICE, UAA and ICUD6 guidelines do not recommend both diuretics and desmopressin as the main treatments for LUTS; however, they are options for patients with nocturnal polyuria, for patients in whom other medical causes have been excluded, and for patients who have not benefited from other standard treatments.

None of the guidelines recommended phytotherapeutric drugs as standard treatment for LUTS, although some guidelines cited inconsistent evidence suggesting the pos- sibility of Serenoa repens in improving both IPSS and Qmax. Intraprostatic botulinum injection was still experimental and generally not recommended unless offered as a part of a randomized controlled trial. Beta-3 agonists were mentioned in the ICUD guideline as a new emerging agent, mainly for overactive bladder.

\section{Minimally invasive therapies recommendations}

Across the guidelines, minimally invasive therapies, specifically transurethral microwave therapy and transurethral needle ablation of prostate, were considered as alternatives in patients with moderate or severe LUTS, with small to moderate gland size, and with the desire to avoid invasive therapy due to clinical risk for cardiopulmonary complication (Table 4). However, these treatments were not recommended as a primary treatment for LUTS; the NICE guideline has particularly recommended avoiding these alternatives for patients without a contraindication to standard surgery, such as transurethral resection of the prostate (TURP), trans-

\begin{tabular}{|c|c|c|c|c|c|c|c|c|c|c|}
\hline Pharmacologic therapy & AUA & EAU & NICE & $\begin{array}{l}\text { JUA } \\
2009\end{array}$ & $\begin{array}{l}\text { JUA } \\
2011\end{array}$ & $\begin{array}{l}\text { CUA } \\
2010\end{array}$ & $\begin{array}{l}\text { CUA } \\
2012\end{array}$ & UAA & BAUS & ICUD6 \\
\hline Alpha-blockers & & & & & & & $\mathrm{R}$ & $\mathrm{R}$ & ND & \\
\hline Alfuzosin & $\mathrm{O}$ & $\mathrm{R}$ & $\mathrm{R}$ & NR & NR & $\mathrm{O}$ & & & ND & $\mathrm{R}$ \\
\hline Doxazosin & $\mathrm{O}$ & $\mathrm{R}$ & $\mathrm{R}$ & ND & ND & $\mathrm{O}$ & & & ND & $\mathrm{R}$ \\
\hline Phenoxybenzamines & ND & ND & ND & ND & ND & ND & & & ND & ND \\
\hline Prazosin & NR & ND & ND & $\mathrm{R}$ & $\mathrm{R}$ & ND & & & ND & ND \\
\hline Tamsulosin & $\mathrm{O}$ & $\mathrm{R}$ & $\mathrm{R}$ & $\mathrm{R}$ & $\mathrm{R}$ & $\mathrm{O}$ & & & ND & $\mathrm{R}$ \\
\hline Terazosin & 0 & $\mathrm{R}$ & $\mathrm{R}$ & $\mathrm{R}$ & $\mathrm{R}$ & 0 & & & ND & $\mathrm{R}$ \\
\hline 5-alpha reductase inhibitors & & & $\mathrm{R}$ & & & & $\mathrm{R}$ & $\mathrm{R}$ & ND & \\
\hline Dutasterides & $\mathrm{O}$ & $\mathrm{R}$ & & NR & $\mathrm{R}$ & $\mathrm{O}$ & & & ND & $\mathrm{R}$ \\
\hline Finasterides & $\mathrm{O}$ & $\mathrm{R}$ & & NR & NR & $\mathrm{O}$ & & & ND & $\mathrm{R}$ \\
\hline Phytotherapeutic drugs & NR & NR & ND & NR & NR & NR & ND & NR & ND & NR \\
\hline Anticholinergic drugs & $\mathrm{O}$ & $\mathrm{O}$ & $\mathrm{R}$ & NR & NR & $\mathrm{O}$ & $\mathrm{O}$ & $\mathrm{O}$ & ND & 0 \\
\hline Aromatase inhibitor & ND & ND & ND & ND & ND & ND & ND & ND & ND & NR \\
\hline Beta-3 agonist & ND & ND & ND & ND & ND & ND & ND & ND & ND & $\mathrm{O}$ \\
\hline Botox & ND & NR & NR & ND & NR & NR & ND & NR & ND & NR \\
\hline PDE5i & ND & $\mathrm{O}$ & NR & NR & NR & NR & NR & $\mathrm{O}$ & ND & NR \\
\hline Loop diuretics & ND & ND & $\mathrm{O}$ & ND & ND & ND & ND & ND & ND & NR \\
\hline Desmopressin & ND & $\mathrm{O}$ & $\mathrm{O}$ & ND & ND & ND & ND & $\mathrm{O}$ & ND & $\mathrm{O}$ \\
\hline Alpha blocker +5 a reductase & $\mathrm{O}$ & $\mathrm{R}$ & $\mathrm{O}$ & NR & ND & $\mathrm{O}$ & $\mathrm{R}$ & $\mathrm{R}$ & ND & $\mathrm{R}$ \\
\hline Alpha blocker + muscarinic & ND & $\mathrm{O}$ & $\mathrm{O}$ & NR & NR & $\mathrm{O}$ & $\mathrm{O}$ & $\mathrm{O}$ & ND & $\mathrm{O}$ \\
\hline Alpha blocker + PDE5i & ND & ND & ND & ND & ND & ND & ND & $\mathrm{O}$ & ND & ND \\
\hline Urapidil (Alpha 1 A selective) & ND & ND & ND & $\mathrm{R}$ & $\mathrm{R}$ & ND & ND & ND & ND & ND \\
\hline Naftopidil & ND & ND & ND & $\mathrm{R}$ & $\mathrm{R}$ & ND & ND & ND & ND & ND \\
\hline Silodosin & ND & ND & ND & $\mathrm{R}$ & $\mathrm{R}$ & ND & ND & ND & ND & ND \\
\hline Chlormadinone, allylestrenol & ND & ND & ND & NR & NR & ND & ND & ND & ND & ND \\
\hline NSAIDS & ND & ND & NR & ND & ND & ND & ND & ND & ND & ND \\
\hline
\end{tabular}

M: if mandatory or compulsory is described in the guideline; R: recommendation for general and in special condition; O: optional; NR: not recommended; ND: not discussed; NICE: National

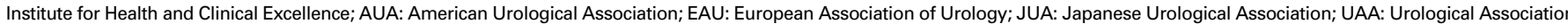
of Asia; CUA: Canadian Urological Association; ICUD: International Consultation on Urological Diseases; BAUS: British Association of Urological Surgeons; PDE5i: phosphodiesterase type 5 inhibitors; NSAIDS: nonsteroidal anti-inflammatory drugs. 
urethal vaporization of the prostate (TUVP) or holmium laser enucleation of the prostate (HoLep). Prostatic stents were also mentioned in the EAU, JUA 2011, CUA 2010, UAA and ICUD6 guidelines as alternatives for catheterization for patients with significant comorbidities deemed unfit for surgery. Interstitial laser coagulation of the prostate was also listed by the JUA 2011 and ICUD6 guidelines as an option and may be effective and feasible, although it has rare serious adverse reactions; however, long-term benefits were not sustained. Other minimally invasive approaches, such as balloon dilatation, water induced thermotherapy (WIT), absolute ethanol injection, transurethral ethanol ablation of prostate (TEAP), and high intensity focused ultrasound, were generally not recommended to treat LUTS, particularly due to insufficient evidence to show their efficacy and safety.

\section{Surgical recommendations}

The main indication for surgery among LUTS patients include renal insufficiency secondary to $\mathrm{BPH}, \mathrm{BOO}$ with benign prostatic enlargement (BPE), and recurrent UTIs, bladder stones or gross hematuria due to $\mathrm{BPH}$, and LUTS refractory to medical therapies (Table 4). The AUA guideline particularly cited that the presence of a bladder diverticulum was not an absolute indication for surgery unless associated with recurrent UTI or progressive bladder dysfunction. However, as a standard, the urologist should discuss outcomes from surgery and any alternatives to surgery.

All guidelines listed TURP as the current surgical procedure for prostates sized 30 to $80 \mathrm{~g}$ and for patients with moderate-to-severe LUTS secondary to benign prostatic obstruction, and has been the mainstay of treatment for symptomatic BPE due to its combined high consistent effectiveness with an acceptable side effect profile. Other acceptable surgical options and almost equally effective as TURP were bipolar transurethral resection in saline (TURIS), holmium laser enucleation of the prostate (HoLEP), TUVP (transurethal vaporization of the prostate), and photoselective vaporization prostatectomy (PVP). These alternatives were only recommended if availability and expertise in executing these specialized techniques were not a problem. Likewise, the transurethral incision of the prostate (TUIP) was cited by all guidelines as the treatment of choice in selected LUTS patients, particularly those with bothersome moderate-

Table 4. Minimally invasive therapy, surgical, conservative and other considerations: Recommendation summary across the guidelines

\begin{tabular}{|c|c|c|c|c|c|c|c|c|c|c|}
\hline & AUA & EAU & NICE & $\begin{array}{l}\text { JUA } \\
2009\end{array}$ & $\begin{array}{l}\text { JUA } \\
2011\end{array}$ & $\begin{array}{l}\text { CUA } \\
2010\end{array}$ & $\begin{array}{l}\text { CUA } \\
2012\end{array}$ & UAA & BAUS & ICUD6 \\
\hline TUMT & $\mathrm{O}$ & $\mathrm{O}$ & NR & ND & $\mathrm{O}$ & $\mathrm{O}$ & ND & $\mathrm{R}$ & ND & $\mathrm{O}$ \\
\hline TUNA & $\mathrm{O}$ & $\mathrm{O}$ & NR & ND & $\mathrm{O}$ & $\mathrm{O}$ & ND & $\mathrm{R}$ & ND & $\mathrm{O}$ \\
\hline Prostatic stent & ND & $\mathrm{O}$ & ND & ND & $\mathrm{O}$ & $\mathrm{O}$ & ND & $\mathrm{O}$ & ND & 0 \\
\hline Balloon dilatation & ND & ND & ND & ND & ND & ND & ND & ND & ND & $\mathrm{NR}$ \\
\hline ILC & ND & ND & ND & ND & $\mathrm{O}$ & ND & ND & ND & ND & $\mathrm{O}$ \\
\hline WIT & ND & ND & ND & ND & ND & NR & ND & ND & ND & NR \\
\hline HIFU & ND & ND & NR & ND & $\mathrm{O}$ & NR & ND & ND & ND & ND \\
\hline TEAP & ND & ND & NR & ND & NR & ND & ND & ND & ND & NR \\
\hline Absolute ethanol injection & ND & NR & NR & ND & ND & NR & ND & ND & ND & ND \\
\hline \multicolumn{11}{|c|}{ Surgical therapies } \\
\hline TUIP & $\mathrm{O}$ & $\mathrm{R}$ & $\mathrm{O}$ & ND & $\mathrm{R}$ & $\mathrm{O}$ & ND & $\mathrm{R}$ & ND & $\mathrm{O}$ \\
\hline TURP & $\mathrm{O}$ & $\mathrm{R}$ & $\mathrm{R}$ & $\mathrm{R}$ & $\mathrm{R}$ & $\mathrm{R}$ & ND & $\mathrm{R}$ & ND & $\mathrm{R}$ \\
\hline Open prostatectomy & 0 & $\mathrm{R}$ & 0 & ND & 0 & 0 & ND & 0 & ND & $\mathrm{R}$ \\
\hline TUVP & $\mathrm{O}$ & ND & $\mathrm{O}$ & ND & ND & ND & ND & ND & ND & $\mathrm{O}$ \\
\hline HoLEP & $\mathrm{O}$ & $\mathrm{O}$ & $\mathrm{O}$ & ND & $\mathrm{R}$ & $\mathrm{O}$ & ND & $\mathrm{R}$ & ND & $\mathrm{R}$ \\
\hline VLAP & $\mathrm{O}$ & ND & NR & ND & ND & ND & ND & ND & ND & $\mathrm{O}$ \\
\hline TURIS & $\mathrm{O}$ & $\mathrm{O}$ & $\mathrm{O}$ & ND & $\mathrm{R}$ & $\mathrm{O}$ & ND & ND & ND & ND \\
\hline PVP: GreenLight Laser & $\mathrm{O}$ & $\mathrm{O}$ & $\mathrm{O}$ & ND & $\mathrm{O}$ & $\mathrm{O}$ & ND & $\mathrm{O}$ & ND & ND \\
\hline Lap or robot prostatectomy & $\mathrm{O}$ & ND & ND & ND & ND & ND & ND & ND & ND & ND \\
\hline Lifestyle modifications & $\mathrm{R}$ & M & $\mathrm{O}$ & $\mathrm{R}$ & $\mathrm{R}$ & $\mathrm{R}$ & ND & $\mathrm{R}$ & ND & $\mathrm{O}$ \\
\hline Watchful waiting & M & $\mathrm{R}$ & $\mathrm{O}$ & $\mathrm{R}$ & $\mathrm{O}$ & $\mathrm{R}$ & ND & $\mathrm{R}$ & ND & $\mathrm{O}$ \\
\hline $\begin{array}{l}\text { Urethral catheter; suprapubic } \\
\text { tube catheter }\end{array}$ & ND & ND & $\mathrm{O}$ & $\mathrm{R}$ & $\mathrm{O}$ & ND & ND & 0 & ND & ND \\
\hline Intermittent catheterization & ND & ND & $\mathrm{O}$ & $\mathrm{R}$ & $\mathrm{O}$ & ND & ND & $\mathrm{O}$ & ND & ND \\
\hline
\end{tabular}

\footnotetext{
M: if mandatory or compulsory is described in the guideline; R: recommendation for general and in special condition; O: optional; NR: not recommended; ND: not discussed; TUMT:
} transurethral microwave therapy; TUNA: transurethral needle ablation; ILC: interstitial laser coagulation; WIT: water induced thermotherapy; HIFU: high intensity focused ultrasound; TUIP:

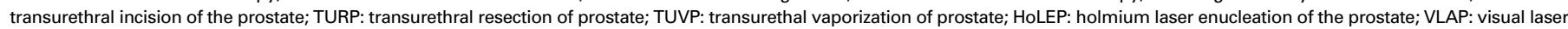
ablation of the prostate; TURIS: bipolar transurethral resection in saline; PVP: photoselective vaporization prostatectomy; TEAP: transurethral ethanol ablation of the prostate. 
to-severe LUTS with prostate sizes $<30 \mathrm{~g}$ and without prostate middle lobes. Open prostatectomy was considered for large prostate glands ( $>80 \mathrm{~g}$ ) or LUTS with evident BPE that have associated complications, such as large bladder stones or bladder diverticula. The laparoscopic or robotic-assisted prostatectomy was not well-discussed in the guidelines. Conservative management and other recommendations Conservative management, including watchful waiting and lifestyle modification, were considered standards of care for men with mild symptoms of LUTS or patients who were not bothered by their symptoms (Table 4). We tallied the recommended lifestyle modifications, as described by the NICE, EAU, UAA and CUA 2010 guidelines (Table 5). Other conservative treatments for LUTS included biofeedback, pelvic floor muscle training, electrical stimulation, and containment products. The NICE, JUA and UAA guidelines considered intermittent bladder catheterization for men with voiding LUTS that cannot be corrected by less invasive measures, and only if other treatments were impractical. Indwelling urethral or suprapubic catheters were offered to treat urinary retention in cases where other therapies could not be administered or were unsuccessful, or in patients with skin wounds, pressure ulcers or who were unable to manage intermittent self-catheterization.

\section{Discussion}

In 2006, Novara and colleagues provided a critical overview of clinical guidelines for $\mathrm{BPH}$; they found considerable differences in guidelines, particularly regarding methodological issues. ${ }^{19}$ Their assessments were based on AGREE appraisal instruments, and they found that the 2000 Australian National Health and Medical Research Council (NHMRC) and the AUA 2004 guidelines had the highest overall scores. In contrast to their critical review, with the updated AGREE II tool CPG assessment used in our critical review, we were able to determine that the NICE guideline, AUA and EAU guidelines have higher scores among the recent guidelines available for non-neurogenic male LUTS. The lowest domain scores were in "applicability" and "editorial independence," which were the domain assessment for organizational changes and related implications in monitoring guideline applications. Likewise, there is no influence of the funding body on the recommendation and all group members declared any possible conflicts of interest.

Most of the guidelines focused on managing $\mathrm{BPH}$ as a cause of LUTS, while the NICE, EAU, ICUD6 and JUA 2009 guidelines tackled LUTS with other etiologies. Likewise most guidelines were intended for urologists, except for the BAUS, JUA 2009 and 2011 guidelines, which were tailored for non-urologists. The UAA, ICUD6, AUA, and NICE guidelines had specifically explained the initial basic workup and management for the general practitioner and any specifics for specialist assessment and management.

In contrast to the linear relationship noted by Novara and colleagues and Irani and colleague that high-score guidelines recommended fewer tests, ${ }^{19,20}$ our findings did not reveal any correlation with the number of recommended tests and score of the guidelines. In fact the AGREE II assessment of a guideline mainly focused on how well the guideline was developed, processed, and reported; it does not guarantee that a highly scored guideline will provide excellent recommendations. We recommend that the domain on rigor of development and stakeholder involvement be more prominent in the evaluation process. The AGREE II assessment strongly recommends assessing guidelines individually rather tallying total scores. That being said, the NICE, AUA and EAU guidelines were the top 3 highest ranked in these domains. A good guideline must clearly consider the effectiveness of the diagnostic and management recommendations, while weighing the economic considerations, risks and benefit. A good guideline that will be widely applied must clearly consider the effectiveness of the diagnostic and management recommendations, while weighing the economic considerations, risks and benefits. In a commentary by Dans and Dans, the equity of the recommended management must be considered when adapting certain recommendations for personal practice. ${ }^{21}$ Basically, clinical practice guidelines

\section{Table 5. Summary of specific lifestyle modifications as described by various guidelines}
a. Fluid intake modifications with restriction of fluid intake at specific times for patients with storage symptoms. The recommend total daily fluid intake for patients with LUTS should be 1500-2000 mL. Fluid restriction 2 hours prior to sleeping to decrease nocturia.
b. Avoidance or moderation of dietary factors that may have a diuretic and irritant effect (i.e., caffeine, alcohol, and spices).
c. Use of double-voiding techniques, relaxed voiding, and urethral stripping to prevent post micturition dribble.
d. Distraction techniques (i.e., penile squeeze, breathing exercises, perineal pressure and mental 'tricks') to control irritative symptoms such as urgency.
e. Bladder re-training, by encouragement to 'hold on' at time of urgency sensation to increase bladder capacity (about $400 \mathrm{~mL}$ ) and the time between voids.
f. Optimizing the time of medication administration or prescribing appropriate drugs that have fewer urinary effects.
g. Provide assistance for impairment of dexterity, mobility or mental state.
h. Avoid and treat constipation.
i. Education and reassurance
LUTS: lower urinary tract symptoms. 
Chua et al.

serve as a good guide based on the best available evidence; while management of each patient should be on a case by case basis.

\section{Conclusion}

The quality of recent CPGs on non-neurogenic male LUTS were appraised and summarized. The NICE, AUA and EAU guidelines were highly compliant to the AGREE II proposition for guideline formation and development. The recommendations of these three guidelines in initial assessment, medical management, and surgical approach were similar, but with a discrepancy in recommending minimally invasive therapy as an alternative approach to treat LUTS. Our critical review should serve as a summary of the guideline recommendations. Readers are encouraged to use the data to select which guideline is the most appropriate for their local practice.

Acknowledgements: The authors would like to thank Dr. Marie Carmela Lapitan, who served as our methodologist advisor and gave us constructive comments for improvement of the draft manuscript. Also to Dr. Fideliz V.Gutierrez, who did a comprehensive English language check on our draft manuscript.

Competing interests: The authors declare no competing financial or personal interests.

This paper has been peer-reviewed.

\section{References}

1. Kupelian V, Wei JT, O'Leary MP, et al.; BACH Survery Investigators. Prevalence of lower urinary tract symptoms and effect on quality of life in a racially and ethnically diverse random sample: The Boston Area Community Health (BACH) Survey. Arch Intern Med 2006;166:2381-7. http://dx.doi.org/10.1001/ archinte.166.21.2381

2. Maserejian NN, Chen S, Chiu GR, et al. Treatment status and progression or regression of lower urinary tract symptoms among adults in a general population sample. J Urol 2014;191:107-13.

3. Graham R, Mancher M, Wolman DM, et al. Clinical Practice Guidelines We Can Trust. Institute of Medicine. Washington, DC: National Academies Press; 2011:4-10.
4. Ransohoff DF, Pignone M, Sox HC. How to decide whether a clinical practice guideline is trustworthy. JAMA 2013;309:139-40. http://dx.doi.org/10.1001/jama.2012.156703

5. AGREE Next Steps Consortium. The AGREE II Instrument: Electronic version. http://www.agreetrust. org. Accessed July 6, 2015

6. Polus S, Lerberg P, Vogel J, et al. Appraisal of WHO Guidelines in Maternal Health Using the AGREE II Assessment Tool. PLoS ONE 2012;7:e38891. http://dx.doi.org/10.1371/journal.pone.0038891

7. Liberati A, Altman DG, Tetzlaff J, et al. The PRISMA statement for reporting systematic reviews and meta-analyses of studies that evaluate healthcare interventions: explanation and elaboration. BMJ 2009:339:b2700. http://dx.doi.org/10.1136/bmi.b2700

8. Brouwers M, Kho ME, Browman GP, et al.; for the AGREE Next Steps Consortium. AGREE II: Advancing guideline development, reporting and evaluation in healthcare. Can Med Assoc J 2010;182:E839-42. http://dx.doi.org/10.1503/cmaj.090449

9. National Institute for Health and Clinical Excellence (NICE). Management of lower urinary tract symptoms in men; 2010. www.nice.org.uk. Accessed July 6, 2015.

10. McVary KT, Roehrborn CG, Avins AL, et al. Update on AUA Guideline on the Management of Benign Prostatic Hyperplasia. J Urol 2011;185:1793-803. http://dx.doi.org/10.1016/i.juro.2011.01.074

11. Oelke $M$, Bachmann $A$, Descazeaud $A$, et al. Guidelines on management of male lower urinary tract symptoms (LUTS), incl. benign prostatic obstruction (BPO). European Association of Urology; http:// uroweb.org/wp-content/uploads/Non-Neurogenic-Male-LUTS_2705.pdf. Accessed July 6, 2015.

12. Homma Y, Araki I, Igawa $Y$, et al. Clinical guideline for male lower urinary tract symptoms. Int I Urol 2009;16:775-90. htrp://dx.doi.org/10.1111/j.1442-2042.2009.02369.x

13. Homma $Y$, Gotoh $M$, Yokoyama 0 , et al. JUA clinical guidelines for benign prostatic hyperplasia (JUA). Int J Urol 2011;18:el-33. http://dx.doi.org/10.1111/i.1442-2042.2011.02861.x

14. Takeda M, Rahman A, Salam MA, et al. UAA Consensus on the Management of BPH/Male LUTS. http:// uaanet.org/images/BPH\%20guidelines.pdf. Accessed July 6, 2015.

15. Nickel JC, Méndez-Probst CE, Whelan TF, et al.; the Canadian Prostate Health Council and the CUA Guidelines Committee. 2010 Update: Guidelines for the management of benign prostatic hyperplasia CUA Guideline. Can Urol Assoc J 2010;4:310-6. http://dx.doi.org/10.5489/cuaj.10124

16. Roehrborn C. Benign prostatic hyperplasia and lower urinary tract symptom Guidelines. Can Urol Assoc J 2012;6:S130-2. http://dx.doi.org/10.5489/cuaj.12231

17. Abrams $\mathrm{P}$, Chapple $\mathrm{C}$, Khoury $\mathrm{S}$, et al. Evaluation and treatment of lower urinary tract symptoms in older men. J Urol 2013;189:S93-S101. http://dx.doi.org/10.1016/i.juro.2012.11.021

18. Kirby R, Anderson J, Joyce A. Diagnosis of lower urinary tract symptoms resulting from benign prostatic hyperplasia (BAUS). Innovait 2012 August 2.

19. Novara $G$, Galfano $A$, Gardi $M$, et al. Critical review of guidelines for $B P H$ diagnosis and treatment strategy. Eur Urol Suppl 2006;5:418-29. http://dx.doi.org/10.1016/i.eursup.2006.02.005

20. Irani J, Brown CT, Van der Meulen J, et al. A review of guidelines on benign prostatic hyperplasia and lower urinary tract symptoms: Are all guidelines the same? BJU Int 2003;92:937-42. http://dx.doi. org/10.1111/j.1464-410X.2003.04529.x

21. Dans AL, Dans LF. Appraising a tool for guideline appraisal (the AGREE II instrument): Commentaries. J Clin Epidemiol 2010;63:e1281-2. http://dx.doi.org/10.1016/i.jlinepi.2010.06.005

Correspondence: Dr. Michael Erlano Chua, Institute of Urology, St. Luke's Medical Center, Manila, Philippines; auhc_ekim@yahoo.com 